\title{
Sistem Pendukung Keputusan \\ Seleksi Visa-Kitas Lansia Menggunakan Metode Fuzzy MADM (STUDI KASUS: PT. Mulia Prima Permai)
}

\author{
Putri Taqwa Prasetyaningrum (1), Dhana Sudana ${ }^{(2)}$ \\ Program Studi Sistem Informasi, Fakultas Teknologi Informasi \\ Universitas Mercu Buana Yogyakarta \\ e-mail: putri@mercubuana-yogya.ac.id(1)
}

\begin{abstract}
The selection of elderly visa-kitas receiver to asses the cantidate who qualify at PT Mulia Prima Permai Jakarta is not an easy process. The difficulty of the procedure require in Embassy makes PT Mulia Prima Permai needs to choose the most effective way to do the selection of elderly visa applicants before sending it to the Embassy. One of the options is by using the decision making of Fuzzy Multi Attribute Dictition Making (MADM) method. The Fuzzy Multi Attribute Diction Making Method is expected can help to solve the problem of elderly visa acceptance selection effectively. In this research, it is necessary to compile some criteria and alternatives. To support the selection process of acceptance for the elderly visa kitas a Decision Support System of selection was created by using Fuzzy Multi Attribute Dicision Making (MADM) method. The Decision Support System is useful to process the required data (input) of elderly visa kitas application and outcome the request status output in the form that $100 \%$ match the results of the calculation with PT. Mulia Prima Permai.
\end{abstract}

Keywords: Fuzzy Multi Attribute Dicision Making (MADM), Elderly visa-kitas selection, Decission support system

Abstrak
Seleksi penerimaan visa-kitas lansia, untuk menilai calon peserta yang memenuhi syarat di
PT.Mulia Prima Permai Jakarta bukanlah suatu kegiatan yang mudah. Banyaknya prosedur
seleksi pada tingkat Dirjen Imigrasi, membuat PT.Mulia Prima Permai harus mengambil
keputusan yang tepat untuk menyeleksi persyartan pemohon visa sebelum dikirim ke Dirjen
Imigrasi, ini menjamin permohonan visa-kitas dapat dipertangung-jawabkan dan disetujui. Salah
satu solusi dalam memecahkan masalah seleksi penerimaan visa kitas lansia tersebut adalah
dengan pengambilan keputusan metode Fuzzy Multi Attribute Dicision Making (MADM).
Metode Fuzzy Multi Attribute Dicision Making dapat membantu menyelesaikan permasalahan
seleksi penerimaan visa kitas lansia tersebut dengan efektif. Dalam penelitian ini, untuk
mendapatkan solusi pengambilan keputusan seleksi penerimaan visa kitas lansia tersebut,
perlu disusun beberapa kriteria dan alternatif. Untuk membantu proses seleksi penerimaan visa
kitas lansia tersebut, maka dibuat sebuah Sistem Pendukung Keputusan seleksi penerimaan
visa kitas lansia tersebut dengan menggunakan metode Fuzzy Multi Attribute Dicision Making
(MADM). Sistem Pendukung Keputusan berguna untuk mengolah data-data syarat (input)
permohonan visa kitas lansia dan mengahsilkan output status permohonan berupa kesamaan
hasil 98\% cocok terhadap hasil perhitungan PT. Mulia Prima Permai.
Kata kunci: Fuzzy Multi Attribute Dicision Making (MADM), Seleksi visa-kitas lansia,
Sistem Pendukung Keputusan




\section{PENDAHULUAN}

Undang-undangKeimigrasian Indonesia memberikan pengertian tentang visa Republik Indonesia yang selanjutnya disebut visa yaitu, keterangan tertulis yang diberikan oleh pejabat yang berwenang di perwakilan Republik Indonesia atau di tempat lain yang ditetapkan oleh pemerintah Republik Indonesia yang memuat persetujuan bagi orang asing untuk melakukan perjalanan ke wilayah Indonesia dan menjadi dasar untuk pemberian ijin tinggal (www.imigrasi.go.id, imigrasi.go.id, 2016). Ada beberapa tipe visa yang dikeluarkan oleh pemeritah Indonesia; salah satunya repatriasi lansia (ritired).

Ada beberapa kriteria syarat visa lansia yang harus dipenuhi pemohon sebelum dikirim ke Derektoral Jendral Imigrasi di bawah kementrian Hukum dan HAM. Proses seleksi kelengkapan dokumen yang dilakukan selama ini masih memiliki beberapa kelemahan sehingga menimbulkan beberapa persoalan yang berakibat ditolaknya permohonan di Direktoral Jendral Imigrasi.

Merujuk pada penjelasan di atas, penulis akan membuat sebuah sistem pendukung keputusan untuk menyeleksi permohonan visa lansia (Ritiretment Visa) berbasis komputer di PT. Mulia Prima Permai (MPP) Jakarta menggunakan metode Fuzzy Multi-Atribut Decision Making (FMADM). Dimana metode ini sangat efektif untuk menyederhanakan dan mempercepat proses pengambilan keputusan sehingga dapat membantu dalam menentukan status pemohon visa-kitas dengan lebih cepat dan cermat sebelum diproses ke Dirjen Imigrasi

\section{TINJAUAN PUSTAKA}

Sistem Pendukung Keputusan (SPK) atau Decision Support System (DSS) merupakan sistem informasi interaktif yang menyediakan informasi, pemodelan dan pemanipulasian data. Sistem ini digunakan untuk membantu pengambil keputusan dalam situasi yang semi terstruktur dan situasi yang tidak terstruktur dimana tidak seorangpun tahu secara pasti bagaimana keputusan seharusnya dibuat (Kusrini, 2007).

Visa - Kitas lansia (ritiretment visa-kitas) merupakan jenis visa yang di khususkan untuk wisatawan lanjut usia mancanegara. Untuk memperoleh jenis visa ini, orang asing dapat mengajukan permohonannya ke kantor perwakilan Republik Indonesia (konsulat/kedutaan Indonesia diluar negeri) yang terdekat, atau penjaminnya dapat mengajukan ke Direktorat Jenderal Imigrasi setelah melengkapi persyaratannya. (www.imigrasi.go.id, Direktorat Jendral Imgirasi RI, 2014).

Fuzzy Multiple Attribute Decision Making (FMADM) adalah suatu metode yang digunakan untuk mencari alternatif optimal dari sejumlah alternatif dengan kriteria tertentu. Inti dari FMADM adalah menentukan bobot untuk setiap atribut, kemudian dilanjutkan dengan proses perangkingan yang akan menyeleksi alternatif yang sudah diberikan. (Kusumadewi, dkk, 2006).

Ada beberapa metode yang dapat digunakan untuk menyelesaikan masalah FMADM antara lain, (a) Simple Additive Weighting (SAW), (b) Weighted Product (WP), (c) ELECTRE, (d) Tecniques for Order Preference by Similary to Ideal Solution (TOPSIS), dan (e) Analitic Hierarchy Process (AHP) (Kusumadewi, dkk, 2006).

Metode Simple Additive Weighting (SAW) sering juga disebut dengan istilah penjumlahan terbobot. Konsep dasar metode SAW adalah mencari penjumlahan terbobot dari rating kinerja pada setiap alternatif pada semua atribut. Metode SAW membutuhkan proses normalisasi matriks keputusan $(X)$ ke suatu skala yang dapat diperbandingkan dengan semua rating alternatif yang ada (Kusumadewi, dkk 2006). 


\section{METODOLOGI PENELITIAN}

Secara garis besar proses jalannya penelitian ini dibagi menjadi empat tahapan, yaitu : (1) Inteligensi, (2) Desain, (3) Pemilihan, dan (4) Implementasi dan solusi. Selanjutnya jalannya penelitian dapat dilihat pada Gambar 1 .

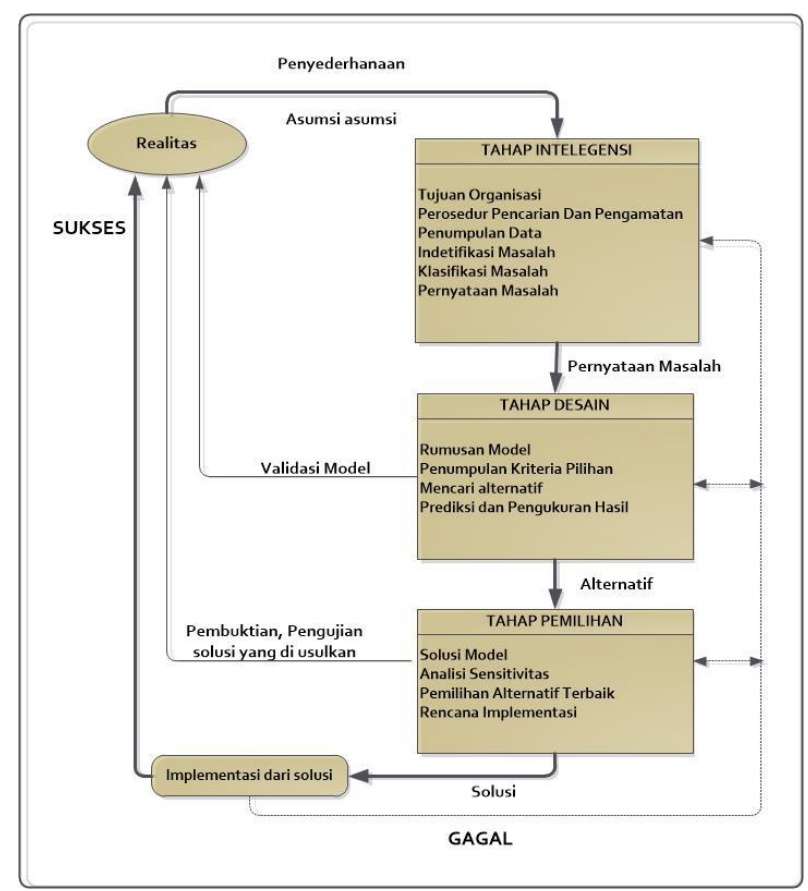

Gambar 1. Model Konseptual Pengambilan Keputusan (Turban, 2005)

\subsection{Intelegensi}

Dalam penelitian teknik pengumpulan data merupakan faktor terpenting demi keberhasilan penelitian, yaitu : (a) Wawancara, (b) Studi Kepustakaan

\subsection{Desain}

Dari masalah yang diuraikan dalam tahap intelegensi, maka dibutuhkan sebuah sistem yang dapat membantu menentukan program studi yang memiliki nilai tertinggi secara cepat, tepat dan mudah dengan pertimbangan kriteria-kriteria yang telah ditentukan, maka untuk kasus perhitungan menentukan program studi tersebut berbasis metode Sistem seleksi visa-kitas lansia Menggunakan Fuzzy Multiple Attribute Decision Making (FMADM) dengan penyelesaian SAW (Simple Additive Weighting). Dalam penyelesaian kasus tersebut berikut langkah yang harus dilakukan :

1. Menentukan kriteria yang digunakan untuk acuan pengambilan keputusan, yaitu : $\mathrm{C} 1$ =Usia, C2 = Dana Pensiun, C3 = Negara asal, C4 = Asuransi, C5 = Sewa Rumah.

2. Berikut standar fuzzyfikasi dari masing-masing kriteria penilaian yang digunakan dalam sistem, seperti pada Tabel 1. 
Tabel 1 Fuzzifikasi

\begin{tabular}{|c|c|c|c|c|c|}
\hline \multirow{2}{*}{ Kriteria } & \multicolumn{5}{|c|}{ Kepentingan } \\
\hline & $\begin{array}{l}\text { Sangat } \\
\text { Baqus }\end{array}$ & Bagus & Cukup & Kurang & Sangat kurang \\
\hline C1 & $\begin{array}{l}\text { usia diatas } \\
70 \text { tahun }\end{array}$ & \begin{tabular}{|l|} 
usia antara \\
65 tahun \\
sampai 69 \\
tahun \\
\end{tabular} & $\begin{array}{l}\text { usia antara } 60 \\
\text { tahun sampai } \\
64 \text { tahun }\end{array}$ & $\begin{array}{l}\text { usia } 55 \text { tahun } \\
\text { sampai } 59 \\
\text { tahun }\end{array}$ & \begin{tabular}{|l|} 
rentang usia \\
dibawah 55 tahun
\end{tabular} \\
\hline C2 & \begin{tabular}{|l} 
Dana \\
pensiun \\
lebih dari
\end{tabular} & \begin{tabular}{|l|} 
antara \\
$2.500-2.999$ \\
dolar/bulan
\end{tabular} & $\begin{array}{c}\text { antara } 2.000- \\
2.499 \\
\text { dolar/bulan }\end{array}$ & $\begin{array}{l}\text { antara } \\
1.500- \\
1.999\end{array}$ & $\begin{array}{l}\text { kurang dari } \\
1.500 \\
\text { dolar/bulan }\end{array}$ \\
\hline C3 & $\begin{array}{c}\text { tingkat } \\
\text { kemakmuran } \\
\text { tinggi }\end{array}$ & $\begin{array}{l}\text { tingkat } \\
\text { kemakmuran } \\
\text { menengah }\end{array}$ & $\begin{array}{c}\text { tingkat } \\
\text { kemakmuran } \\
\text { menengah }\end{array}$ & berkembang & konflik \\
\hline C4 & \begin{tabular}{|c|} 
(platinum) \\
tanggungan \\
maksimal \\
100.000 \\
dolar atau \\
dari negara \\
asal setara \\
dengan nilai \\
tanggungan
\end{tabular} & \begin{tabular}{|l|} 
(gold) \\
tanggungan \\
maksimal \\
75.000 dolar \\
atau dari \\
negara asal \\
setara \\
dengan nilai \\
tanggungan
\end{tabular} & $\begin{array}{c}\text { (silver) } \\
\text { tanggungan } \\
\text { maksimal } \\
30.000 \text { dolar } \\
\text { atau dari } \\
\text { negara asal } \\
\text { setara dengan } \\
\text { nilai } \\
\text { tanggungan }\end{array}$ & $\begin{array}{l}\text { tanggungan } \\
\text { maksimal } \\
25.000 \text { dolar } \\
\text { atau dari } \\
\text { negara asal } \\
\text { setara } \\
\text { dengan nilai } \\
\text { tanggungan }\end{array}$ & $\begin{array}{l}\text { dengan nilai } \\
\text { tanggungan } \\
\text { kurang dari } \\
10.000 \text { dolar atau } \\
\text { tanpa. }\end{array}$ \\
\hline C5 & $\begin{array}{c}\text { harga sewa } \\
\text { lebih dari Rp } \\
40.000 .000 \\
\text { per tahun }\end{array}$ & $\begin{array}{l}\text { harga sewa } \\
\text { lebih dari Rp } \\
30.000 .000 \\
\text { per tahun }\end{array}$ & $\begin{array}{l}\text { dengan harga } \\
\text { sewa lebih } \\
\text { dari Rp } \\
20.000 .000 \text {, } \\
\text { per tahun }\end{array}$ & \begin{tabular}{|l} 
harga sewa \\
lebih dari Rp \\
10.000.000, \\
per tahun
\end{tabular} & $\begin{array}{l}\text { harga sewa } \\
\text { kurang dari Rp } \\
10.000 .000 \text {, per } \\
\text { tahun }\end{array}$ \\
\hline
\end{tabular}

3. Menentukan rating kecocokan setiap alternatif pada setiap kriteria. Rating kecocokan setiap alternatif pada setiap kriteria dinilai dengan 0 sampai 1 seperti pada Gambar 2 (a), Sedangkan tingkat kepentingan setiap kriteria berdasarkan nilai bobot (W), dinilai dengan 0 sampai 1 seperti pada Gambar 2 (b)

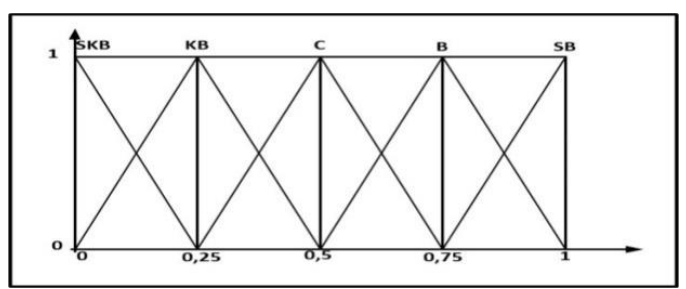

(a)

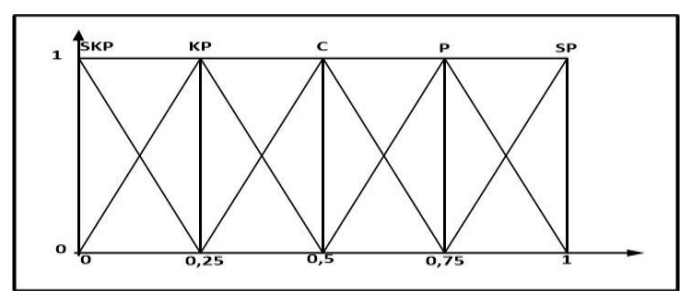

(b)

\section{Gambar 2. Bilangan Fuzzy (a) Untuk Bobot (C), Untuk Bobot (W)}

\subsection{Pemilihan}

Dalam tahap pemilihan ini akan dilakukan langkah ketiga dari penyelesaian dengan metode Fuzzy MADM dengan SAW, yaitu membuat matriks keputusan berdasarkan kriteria, kemudian melakukan normalisasi matriks berdasarkan persamaan yang disesuaikan dengan jenis atribut sehingga diperoleh matriks ternormalisasi $\mathrm{R}$.

1. Menentukan rating kecocokan setiap alternatif pada setiap kriteria.

2. Matriks keputusan $X$ yang telah dikonversikan dengan bilangan fuzzy. 
3. Pengambil keputusan memberikan bobot, berdasarkan tingkat kepentingan masingmasing kriteria yang dibutuhkan.

4. Membuat matriks keputusan $X$, dibuat dari tabel kecocokan.

5. Melakukan normalisasi matriks $\mathrm{R}$ berdasarkan matriks $\mathrm{X}$ untuk menghitung nilai masing-masing kriteria menggunakan persamaan berikut. (S Kusumadewi., dkk, 2006)

$$
r i j= \begin{cases}\frac{X i j}{M a x_{i} X i j} & \rightarrow \text { Jika } j \text { adalah attribut keuntungan } \\ \frac{M i n_{\mathrm{i}} X i j}{X i j} & \rightarrow \text { Jika } j \text { adalah atribut biaya (cost) }\end{cases}
$$

6. Proses perangkingan yaitu penjumlahan dari perkalian matriks ternormalisasi $\mathrm{R}$ dengan vector bobot $\left(W^{*} R\right)$.

\subsection{Implementasi}

\subsubsection{Perancangan Data Flow Diagram}

Data Flow Diagram Level 0 dalam penelitian ini dapat dilihat pada Gambar 3

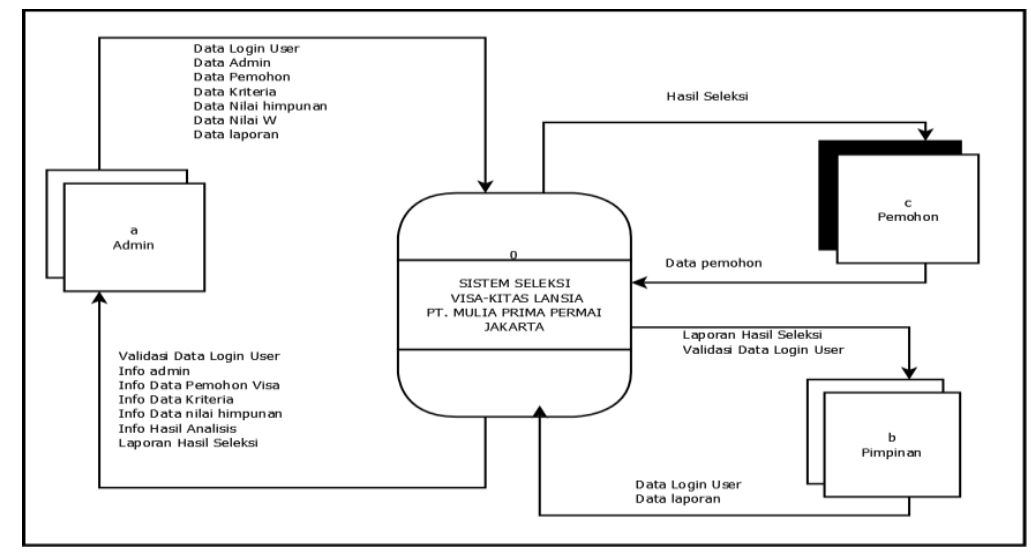

Gambar 3. DFD Konteks

\subsubsection{Flowchart Sistem}

Flowchart sistem pemilihan program studi, dapat dilihat pada Gambar 4

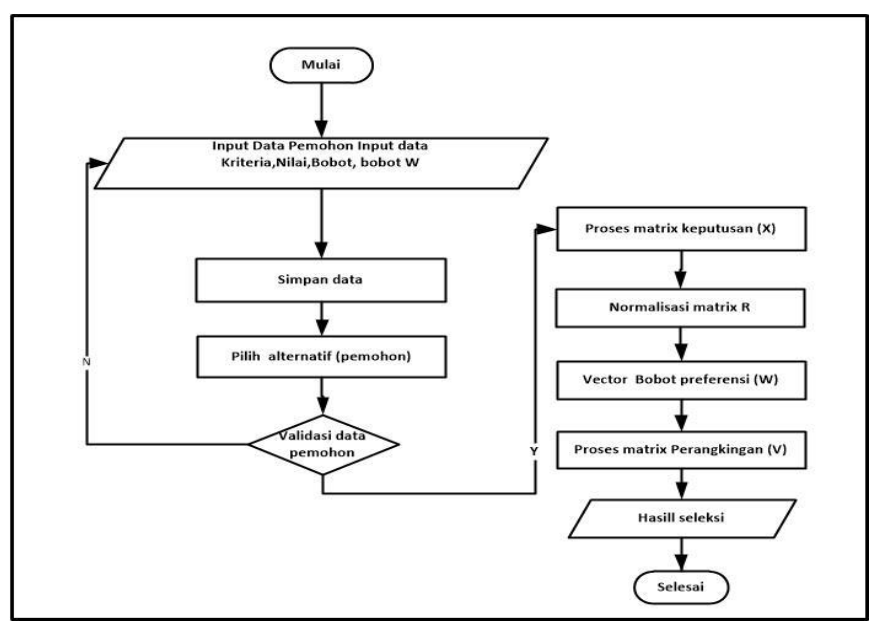

Gambar 4. Flowchart sistem 


\subsubsection{Perancangan Database}

Relasi tabel dalam penelitian ini, dapat dilihat pada Gambar 5.

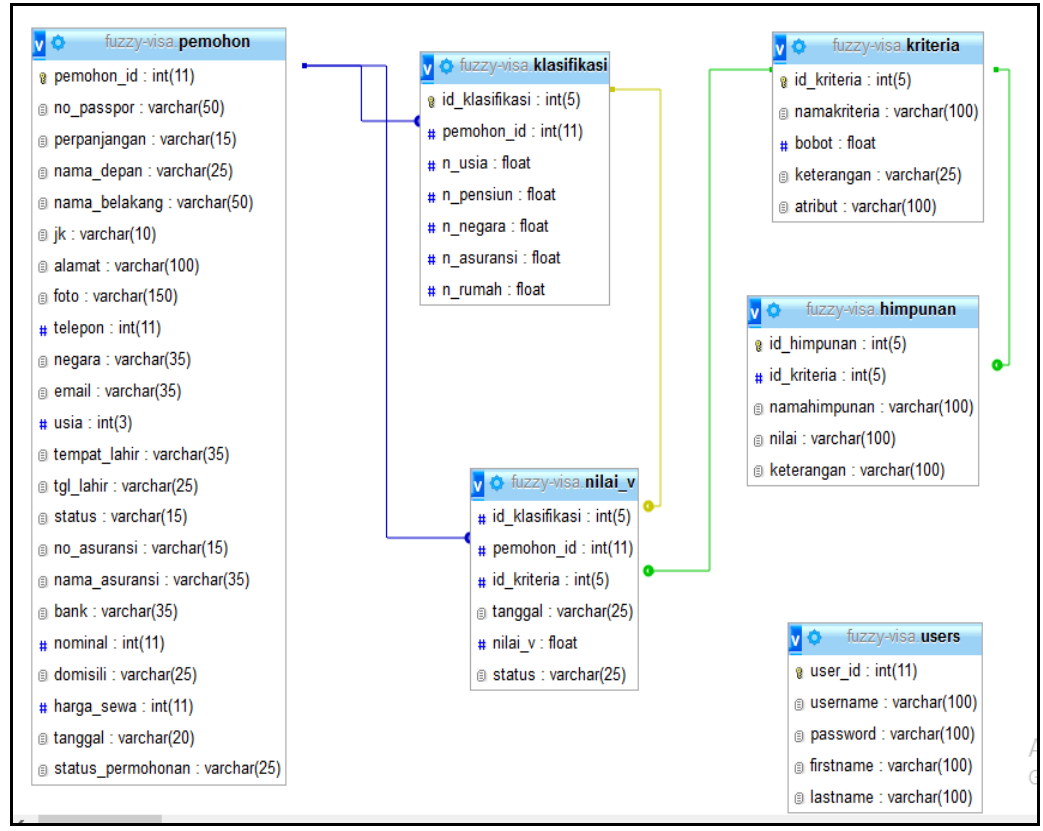

Gambar 5. Rancangan database

\section{PEMBAHASAN}

\subsection{Perhitungan PT.Mulia Prima Permai}

Dalam melakukan seleksi penerimaan visa lansia, PT. Mulia Prima Permai Jakarta masih melakukan perhitungan dengan cara manual, dengan kategori berdasarakan syarat dengan ketentuan syarat usia $25 \%$, dana pensiun $25 \%$, Negara $20 \%$, asuransi $15 \%$ dan sewa rumah 15\%. Dari 12 data pemohon yang diambil diperoleh hasil perhitungan seperti pada Tabel 2.

Tabel 2. Perhitungan Perusahaan

\begin{tabular}{|c|l|c|c|c|c|c|c|}
\hline \multirow{2}{*}{ No } & \multicolumn{1}{|c|}{$\begin{array}{c}\text { Nama } \\
\text { Pemohon }\end{array}$} & \multicolumn{6}{|c|}{ Nilai } \\
\cline { 3 - 8 } & \multicolumn{2}{|c|}{$\begin{array}{c}\text { Usia } \\
(25 \%)\end{array}$} & $\begin{array}{c}\text { Pensi } \\
\text { un } \\
(25 \%)\end{array}$ & $\begin{array}{c}\text { Negar } \\
\text { a } \\
(20 \%)\end{array}$ & $\begin{array}{c}\text { Asuran } \\
\text { si } \\
(15 \%)\end{array}$ & $\begin{array}{c}\text { Sewa } \\
\text { Rumah } \\
(15 \%)\end{array}$ & TOTAL \\
\hline 1 & Paturel, Pierre Henry & 70 & 80 & 90 & 70 & 70 & 76.5 \\
\hline 2 & Neidu, Monica Anna & 80 & 70 & 90 & 80 & 70 & 78 \\
\hline 3 & $\begin{array}{l}\text { Enrique andre } \\
\text { Rodriguez }\end{array}$ & 90 & 50 & 90 & 80 & 50 & 72.5 \\
\hline 4 & Champel, Gerard & 90 & 80 & 90 & 70 & 80 & 83 \\
\hline 5 & Dos Santos, Pedro & 50 & 0 & 90 & 80 & 70 & 54 \\
\hline 6 & Michael, Borloz & 70 & 100 & 90 & 70 & 60 & 80 \\
\hline 7 & Sassi, Guido & 60 & 50 & 90 & 70 & 60 & 65 \\
\hline 8 & Mayer, Gertrud Wolf & 80 & 90 & 90 & 90 & 90 & 87.5 \\
\hline 9 & Simonetta, Maria & 80 & 80 & 90 & 70 & 70 & 79 \\
\hline 10 & $\begin{array}{l}\text { Moriaud, Jean David } \\
\text { Leon }\end{array}$ & 80 & 80 & 90 & 70 & 60 & 77.5 \\
\hline 11 & Wutrich, Rudolf & 80 & 100 & 90 & 90 & 80 & 88.5 \\
\hline 12 & $\begin{array}{l}\text { Rossoud, Phillipe } \\
\text { Jean }\end{array}$ & 80 & 90 & 90 & 90 & 70 & 84.5 \\
\hline
\end{tabular}


Sedangkan pada perhitungan Fuzzy MADM diperoleh hasil perhitungan.yang terlihat pada Tabel 3.

Tabel 3. Hasil perhitungan Fuzzy Madm

\begin{tabular}{|c|l|c|c|}
\hline No & \multicolumn{1}{|c|}{ Nama lengkap } & Alternatif & Nilai \\
\hline 1 & Paturel, Pierre Henry & A1 & 2,50 \\
\hline 2 & Neidu, Monica Anna & A2 & 2,38 \\
\hline 3 & Enrique andre Rodriguez & A3 & 2,63 \\
\hline 4 & Champel, Gerard & A4 & 2.63 \\
\hline 5 & Dos Santos, Pedro & A5 & 1,25 \\
\hline 6 & Michael, Borloz & A6 & 2,38 \\
\hline 7 & Sassi, Guido & A7 & 1,37 \\
\hline 8 & Mayer, Gertrud Wolf & A8 & 3,50 \\
\hline 9 & Simonetta, Maria & A9 & 2,50 \\
\hline 10 & Moriaud, Jean David & A10 & 2,37 \\
\hline 11 & Leon & A11 & 3,38 \\
\hline 12 & Rossoud, Phillipe Jean & A12 & 3,00 \\
\hline
\end{tabular}

\subsection{Pembahasan}

Proses perangkingan menggunakan Fuzzy Multiple Attribute Decision Making (FMADM) dan Simple Additive Weighting (SAW) diperoleh nilai $V$ yang merupakan hasil akhir yang perolehan dari proses perangkingan yaitu penjumlahan dari perkalian matriks ternormalisasi $R$ dengan vektor bobot (V) sehingga diperoleh nilai terbesar yang dipilih sebagai alternatif terbaik (Ai) sebagai solusi, seperti pada Gambar 6.

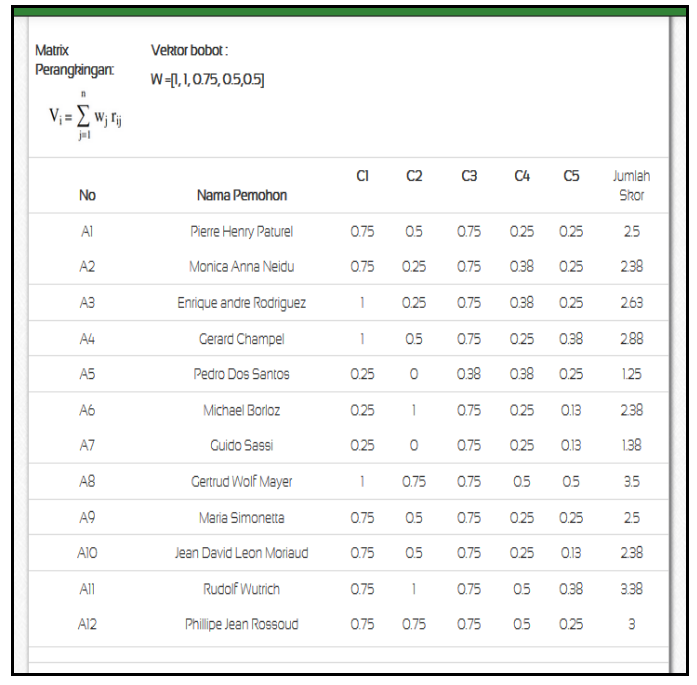

Gambar 6. Hasil Perangkingan FMADM

Hasil penelitian dengan membandingkan penghitungan perangkingan dengan perhitungan metode PT. Mulai Prima Permai Jakarta dan perangkingan dengan menggunakan sistem menunjukkan seperti pada Tabel 4. 
Tabel 2 Analisa Pengujian Seleksi Periode Juni-Juli 2016

\begin{tabular}{|c|c|c|c|c|c|c|c|}
\hline \multirow[t]{2}{*}{ No } & \multirow{2}{*}{$\begin{array}{l}\text { Nama } \\
\text { Pemohon }\end{array}$} & \multirow[t]{2}{*}{ alternatif } & \multicolumn{2}{|c|}{$\begin{array}{l}\text { Hasil Perhitungan } \\
\text { Manual Perusahaan }\end{array}$} & \multicolumn{2}{|c|}{$\begin{array}{l}\text { Hasil Perhitungan } \\
\text { Aplikasi dengan } \\
\text { Metode FMADM }\end{array}$} & \multirow[t]{2}{*}{ Kecocokan } \\
\hline & & & Hasil & Status & Hasil & Status & \\
\hline 1 & \begin{tabular}{|l|} 
Paturel, \\
Pierre \\
Henry \\
\end{tabular} & A1 & 76.5 & Diterima & 2,50 & Direkomendasikan & Sesuai \\
\hline 2 & $\begin{array}{l}\text { Neidu, } \\
\text { Monica } \\
\text { Anna }\end{array}$ & A2 & 78 & Diterima & 2,38 & Direkomendasikan & Sesuai \\
\hline 3 & $\begin{array}{l}\text { Enrique } \\
\text { andre } \\
\text { Rodriguez }\end{array}$ & A3 & 72.5 & Diterima & 2,63 & Direkomendasikan & Sesuai \\
\hline 4 & $\begin{array}{l}\text { Champel, } \\
\text { Gerard }\end{array}$ & A4 & 83 & Diterima & 2.63 & Direkomendasikan & Sesuai \\
\hline 5 & $\begin{array}{l}\text { Dos Santo } \\
\text { Pedro }\end{array}$ & A5 & 54 & Ditolak & 1,25 & Ditolak & Sesuai \\
\hline 6 & \begin{tabular}{|l|} 
Michael, \\
Borloz \\
\end{tabular} & A6 & 80 & Diterima & 2,38 & Direkomendasikan & Sesuai \\
\hline 7 & $\begin{array}{l}\text { Sassi, } \\
\text { Guido } \\
\end{array}$ & A7 & 65 & Ditolak & 1,37 & Ditolak & Sesuai \\
\hline 8 & $\begin{array}{l}\text { Mayer, } \\
\text { Gertrud } \\
\text { Wolf }\end{array}$ & A8 & 87.5 & Diterima & 3,50 & Direkomendasikan & Sesuai \\
\hline 9 & $\begin{array}{l}\text { Simonetta } \\
\text { Maria }\end{array}$ & A9 & 79 & Diterima & 2,50 & Direkomendasikan & Sesuai \\
\hline 10 & $\begin{array}{l}\text { Moriaud, } \\
\text { Jean } \\
\text { David Leol }\end{array}$ & A10 & 77.5 & Diterima & 2,38 & Direkomendasikan & Sesuai \\
\hline 11 & $\begin{array}{l}\text { Wutrich, } \\
\text { Rudolf }\end{array}$ & A11 & 88.5 & Diterima & 3,38 & Direkomendasikan & Sesuai \\
\hline 12 & $\begin{array}{l}\text { Rossoud, } \\
\text { Phillipe } \\
\text { Jean }\end{array}$ & A12 & 84.5 & Diterima & 3,00 & Direkomendasikan & Sesuai \\
\hline
\end{tabular}

Berdasarkan hasil pengujian pada perbandingan antara perhitungan manual perusahaan, dan perhitungan aplikasi sistem menggunakan metode FMADM menggunakan SAW diperoleh nilai akhir yang berbeda, namun keduanya memiliki hasil status yang sama pada semua alternatif dengan paremater asumsi sistem terhadap standar penilaian sistem dihasilkan hasil $98 \%$ yang sama, sehingga ini membuktikan bahwa sistem yang dibuat mempunyai tingkat validitas yang sama dengan perhitungan perusahaan.

\section{KESIMPULAN}

Berdasarkan dari hasil analisis, dan pembuatan sistem seleksi permohonan visa-kitas lansia di PT. Mulia Prima Permai Jakarta, dengan menggunakan metode Fuzzy Multi-Atributte Dicision Making (FMADM), diperoleh kesimpulan bahwa perancangan aplikasi sistem seleksi permohonan visa-kitas lansia di PT. Mulia Prima Permai Jakarta dengan metode Fuzzy MultiAtributte Dicision Making (FMADM) telah selesai dilakukan dengan presentase keberhasilan $98 \%$. Hasil pengujian fungsionalitas menunjukkan bahwa kinerja sistem berjalan sesuai dengan kebutuhan fungsional. Hasil pengujian validitas menunjukkan bahwa sistem yang dibuat mempunyai tingkat validitas yang sama dan sistem sudah melakukan perhitungan dengan 
benar sesuai perhitungan menggunakan algoritma Fuzzy Multi-Atributte Dicision Making (FMADM)

\section{DAFTAR PUSTAKA}

Kusrini. (2007). Konsep dan Aplikasi Sistem Pendukung Keputusan. Yogyakarta: Andi Offset.

Kusumadewi, Sri \& Purnomo H. (2007). Aplikasi Logika Fuzzy untuk Pendukung Keputusan edisi 1. Yogyakarta: Graha Ilmu.

S Kusumadewi., S Hartati., A Harjoko., \& R Wardoyo. (2006). Fuzzy Multi- Atribute Decision Making (Fuzzy MADM). Yogyakarta: Graha Ilmu.

Turban, E. (2005). Decision Support Systems and Intelligent Systems (Sistem Pendukung Keputusan dan Sistem Cerdas). Yogyakarta: Andi.

www.imigrasi.go.id. (2014). Direktorat Jendral Imgirasi RI. Dipetik Mei Kamis tanggal 11 Mei pukul 15.21 wib, 2017, dari Direktorat Jendral Imgirasi RI: http://www.imigrasi.go.id/index.php/layanan-publik/visa-tinggal-terbatas\#persyaratan

www.imigrasi.go.id. (2016, Juli). imigrasi.go.id. Dipetik Maret Jumat Pukul 8.33am, 2017, dari imigrasi.go.id: http://www.imigrasi.go.id/index.php/layanan-publik/kunjungan_visa 